0148 USING THE UK BIOBANK STUDY TO ESTIMATE OCCUPATIONAL CAUSES OF CHRONIC DISEASE: COMPARABILITY WITH THE UK NATIONAL POPULATION AND ADJUSTMENT FOR BIAS

${ }^{1}$ Sally Hutchings, ${ }^{2}$ Jon Ayres, ${ }^{1}$ Paul Cullinan, ${ }^{3}$ David Fishwick, ${ }^{1}$ Debbie Jarvis, ${ }^{1}$ Sara De Matteis, ${ }^{2}$ Steve Sadhra, ${ }^{1}$ Magda Wheatley, 'Lesley Rushton. ${ }^{1}$ Imperial College London, London, UK; ${ }^{2}$ University of Birmingham, Birmingham, UK; ${ }^{3}$ Health and Safety Laboratory, Buxton, UK

\subsection{6/oemed-2014-102362.245}

Objectives The UK Biobank study is a sample of 502,682 people aged 40-70, clustered around 22 assessment centres. As part of a project to investigate the causes of COPD and estimate the UK occupational burden, we have assessed the sample's representativeness with respect to the UK national population, with a view to accounting for potential biases.

Method We have compared characteristics of the Biobank population (age, education, employment, smoking etc) to that of the UK population as estimated from national data sources.

Results Deprivation index scores indicate that Biobank respondents in more affluent wards are over-represented $(52 \%$ of Biobank respondents versus $28 \%$ nationally have scores of less than -2). The Biobank respondents are also better-educated (33\% to degree level, 17\% nationally), with similar qualification levels in men and women, whereas more men than women nationally in this age range had higher level qualifications. Fewer were currently employed than nationally $(58 \%$ vs. $65 \%)$, particularly men over 60 , with more retired ( $45 \%$ vs. $33 \%$ ), and fewer disabled or unemployed. There are more in managerial and professional (54\% vs. 46\%), and fewer in routine and manual occupations (22\%, 33\% nationally), and fewer smokers (33\% vs. 49\%). Fewer in the already under-represented unskilled occupations ( $47 \%$ vs. $70 \%$ for other occupations), or with reported respiratory ill-health (50\% vs. $59 \%)$ have a usable email address.

Conclusions As Biobank respondents are on average less deprived, better educated and under-represented in unskilled occupations than the national population, estimating national occupational COPD burden, and collecting further data without bias will require data adjustments.

\section{BRAZILIAN CONSTRUCTION INDUSTRY: A CONTRIBUTION TO IMPROVE INFORMATION ON FATAL WORK ACCIDENTS}

Celso Salim. Fundacentro, Belo Horizonte, Minas Gerais State, Brazil

\subsection{6/oemed-2014-102362.246}

Objectives Considering data sources and statistical trends on recent fatal cases resulting from workplace accidents in the Brazilian construction industry, herein two aspects are emphasised: a critical appraisal of the official registers on deaths resulting from work-related accidents, and a discussion on alternatives to achieve better information to support interventions in this sector.

Method Statistics and the variability in the profiles of death at work from 2000 to 2011 were systematically analysed for construction industry according to the federal data sources on dimensions related to occupational health, working conditions and social security.

Results In addition to presentation of specific rates and a set of indicators, a technical proposal is suggested for a more effective and realistic characterisation of the profile of mortality in workplaces by considering age, gender, education, occupation, as well the more frequent causes related to each type of accident. All of them as a condition to understand the main risks and to help teams of OSH facing the worst violence against workers.

Conclusions By reason of the high social and economic costs involving work accidents in Brazil, this study searches to provide a specific comprehension on fatal cases as well as some subsidies for the government to draw policies oriented to minimise risks in the workplaces of construction industry. However, mortality resulting from accidents in the informal labour market should be considered to overcome gap on information. After all, if the number of unemployed workers is underestimated, the number of underemployed has not been taken into account.

\section{ANALYSIS OF WORK RELATED ACCIDENTS IN THE MINING SECTOR 2000-10: THE CASE OF MINAS GERAIS STATE, BRAZIL}

Celso Salim. Fundacentro, Belo Horizonte, Minas Gerais State, Brazil

\subsection{6/oemed-2014-102362.247}

Objectives The purpose of this study is to investigate the trends and differentials of workplace accidents registered in the mining sector in the State of Minas Gerais, located in Southeastern Brazil and responsible for more than $40 \%$ of mineral production in the country. In addition, it intends to identify some restraints to more realistic quantifications and characterizations of workplace accidents as well as to discuss possible alternatives to overcome them.

Method Through a critical view of statistics about fatal and nonfatal accidents at workplace originating from Annual Relation of Social Information and Yearly Workplace Accident Records, it is intended to measure differentials about the accident results i.e. temporary incapacity, death and disability, conceive benefits, lost work time, accident description, ages, sex, instruction degree and occupation.

Results From 2000 to 2010, workplace accidents in the mining sector kept a relatively high level. In fact, they are rising. Except for 2001 and mainly for 2003, when it fell, this trend remained practically unchanged in the period. Yet, this fall may not reflect larger outsourcing and/or an increase in informal work relations. Moreover, accident and death rates or lethality rates place the sector in an uncomfortable rank.

Conclusions The data found in these records can be intrinsically improved and their cover range can be broadened. Even keeping the particularities of mining sector on a regional scale, this work shows a concrete analysis followed by propositions of intervention to achieve a better workplace accidents statistics.

\section{SOCIAL SECURITY IN BRAZIL: THE IMPACT OF EPIDEMIOLOGICAL NEXUS ON THE BENEFITS RELATED TO OCCUPATIONAL DISEASES}

Celso Salim. Fundacentro, Belo Horizonte, Minas Gerais State, Brazil

\subsection{6/oemed-2014-102362.248}

Objectives The Ministry of Social Security, in order to face the under-reporting of occupational accidents and diseases, has introduced new methods of identifying them. In addition to the Employment Accident Notification (CAT), the Technical Epidemiological Social Welfare Nexus (NTEP) was established in 2007. This work intends to analyse the role of the NTEP in 